\title{
Engaging with the Private Sector: Nebraska Innovation Campus
}

\section{Harvey Perlman, Chancellor, University of Nebraska}

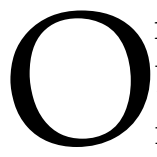

n April 18, 2008, Nebraska Governor Dave Heineman signed Legislative Bill

LB1116 into law, requiring that by 2010, the Nebraska State Fair move from its historic location on 250 acres adjacent to the University of Nebraska-Lincoln to the center of the State in Grand Island. In turn, the bill transferred the property to the University for the purposes of creating Nebraska Innovation Campus. The bill was enacted in the Nebraska Unicameral with only 3 dissenting and 2 abstaining votes, but that did not reflect the intense controversy that led up to its passage.

The University along with several influential business leaders in Lincoln initiated the proposal. The State Fair Board strongly objected. As a statutorily designated member of the State Fair Board, I quietly stopped attending the Board's meetings. The original proposal would have moved the State Fair to another site in Lincoln but, in the end, an agreement was negotiated in which the $\$ 50$ million cost of moving the Fair was borne in various amounts by the City of Grand Island, the State, the University, and the Fair.

As a Fair Board member I knew the condition of the fair grounds. No significant investment had been made there for decades as attendance at the Fair had consistently declined. The buildings were in a sad state of decay, some were no longer open to the public. The utility infrastructure, including water, sewer, and electricity, needed significant upgrades.

It was clear to me and others that the Fair Board had neither the resources nor the revenue to invest in the property and the future of the Fair itself was in jeopardy. But tradition in Nebraska dies hard.
Notwithstanding that since the move the State Fair has prospered in Grand Island far beyond anyone's imagination, there are those who mourn the loss of the September event in Lincoln as well as the economic benefits it was assumed to bring to the city.

So why would the University embroil itself in such a controversy and, more significantly, why would business leaders in Lincoln as well as the City itself support the legislation? And why would the Legislature come eventually to overwhelmingly support adoption of the bill? The reason was the prospects of what a new Innovation Campus could do for the University and the economic future of both the City of Lincoln and the State of Nebraska.

Our proposal, certainly not in itself unique, was to create a research and technology park designed to attract private sector companies to locate adjacent to the University to engage in joint research or other relationships with the University. We predicted that the University would 
occupy one-third of the campus and private sector companies or amenities would occupy two-thirds. Because of the flood plain issues, of the 250 acres, approximately 120 acres are available for development, allowing for approximately 2 million square feet of leasable building space.

We predicted that the campus could generate 5000 jobs and would take from 15 to 20 years to develop. While companies from any sector would be welcome as long as they had a relationship with the University, the priority themes of the campus would be "food, fuel, and water" reflecting the obvious strengths of the University and the primary economic drivers of Nebraska.

During the legislative process I often argued that the infrastructure on the property was obsolete and the Fair had no resources to replace it. With the transfer of the property to the University I discovered, unfortunately, that I had been right about the infrastructure and I was in no better financial position. However, we were able to select a private developer who was willing to make some initial investments, as well as utilize TIF financing to move the project forward.

To date, we have opened two buildings with office space and a conference center. Two more food science laboratory buildings and a set of green houses are under construction. With the exception of the Conference Center, all buildings are owned by and leased from the developer. We have signed our first major private sector tenant, ConAgra Foods, who will expand its joint research with our Food
Science Department, a department we intend to move in its entirety to Innovation Campus.

From the outset we understood that we could not attract private sector companies to locate on a property that was managed by the State and subject to the associated regulatory processes. We created the Nebraska Innovation Campus Development Corporation, an independent 501(c)(3) company managed by a Board of Directors, a majority of whom were from the private sector. NICDC has a ground lease from the University's Board of Regents for the entire property and is the contracting party with the developer or with any future tenants. Thus, the commercial relationships between NICDC and the private companies are shielded from public records laws and other public regulations.

In addition to traditional partnerships with the private sector, two additional facilities are planned for Innovation Campus. The first, an accelerator for start-up companies, will be designed to give a short-term boost to enhance the prospects for success of early stage companies.

The second is what we are calling a "Maker Space." Conceptually, it will be a space with a variety of tools, equipment, and supplies that will allow students, faculty, or community members to join a "Maker's Club" and then to use the facility to "make stuff." We announced a student "Maker's Club" and within three months it is the largest student organization on campus with over 400 members. We hope this, and other activities, will create a real innovation culture that will spread to the rest of the university. 
So, what does all of this have to do with the future of university research? At the risk of stating the obvious, it seems to me there are at least three trends that must be accounted for as we plan our research future.

First, there is the macroeconomic phenomenon that, while innovation is a major driver for economic growth, most public companies are withdrawing from investments in basic research. Driven by the market demands of quarterly income statements as a determinate of stock price, long-term investments without short term returns are problematic. And there is nothing more long-term or uncertain as basic research. Yet, companies also understand they must position themselves to access research that has commercial value and that research takes place largely within universities. Thus there are market forces that make university-private sector partnerships essential.

Second, the continued level of federal research support is uncertain, particularly in this period of political dysfunction in Washington. If Universities are to sustain their core research enterprise, it seems sensible to diversify our sources of funding. Other potential sources are the private sector, international engagements, philanthropy, and internally generated resources.

Third, the political pressure on government expenditures, like the pressure on private sector companies from quarterly income reporting, causes even public funding agencies to demand more evidence of returns from the investments in research. We all know this is shortsighted but we would be foolish to ignore it. Increasingly, federal research funding programs are insisting on proof of commercialization prospects for research proposals or insisting that private sector companies be a partner in funded research.

As seems obvious, all three of these trends dictate that universities develop stronger ties with the private sector as an alternative source of research funding.

Of course, as we have discovered, this is easier to say than to accomplish. Merging the different cultures into a partnership presents some unique challenges. And attempting to account for success or failure also has its complexity. What follows is largely a random set of issues we've seen and steps we've tried to take to address them. They are presented descriptively, not normatively, since it is too soon to know what will be successful and what will not.

The "myth" of adjusting to the "speed of business." We have often heard from business leaders how bureaucratic Universities are and how slow we are in making decisions. If only we could act at the "speed of business".

Of course some of this is true. Public accountability and regulation inevitably build delays into any public organization's decision-making. But private sector companies can also have elaborate bureaucratic processes, particularly when making significant, long-term investment decisions. Market forces can be unrelenting. A change in stock price can instantly alter a company's priorities or at least slow decision-making. Negotiating with several potential partners in recent months convinces me that engagement with the private sector can require pa- 
tience and flexibility. It is also true, however, that one must be ready to respond quickly when a company is ready to engage.

The agreement. Particularly in relationships with companies that are expected to be on-going rather than one-off transactions, reaching a long-term agreement can be a challenging proposition. Private sector lawyers, and university lawyers, are paid to protect their clients from the unexpected. Of course this is a non-sequitur because one cannot plan for the unexpected. Similarly, in longer term relationships, neither party wants to be constantly renegotiating a contract or be in a position where each new initiative requires a new agreement.

We have worked hard to develop master agreements that handle all of the major issues that are likely to arise. Our goal is a situation where, under our master agreements, the only elements needing negotiation for a new initiative are the scope of work and the price. Issues of accountability, reporting, intellectual property, and dispute resolution should all be within the master agreement.

Indeed, probably the most important term of a master agreement is the dispute resolution provisions. You can be assured disputes will arise, and they can do so at the researcher level, at middle-management, or elsewhere in the two organizations. We have tried to include a term in our agreements that specifies how a dispute rises through both organizations for resolution. So, for example, in one of our agreements a dispute at a lower level rises to my office and the company's research vice-president. At that level we hope to negotiate a resolution. This allows the dispute to be put in context of the entire array of joint activities and interests.

In a long term relationship, one cannot look at a single dispute in isolation but rather it must be examined in the context of the larger relationship. (My father was an auto parts wholesaler and he always told me that it doesn't hurt to give into a long term customer on a dispute, even if that customer is wrong. You can always get even in the next transaction.) If we cannot resolve it, the dispute goes to a professional mediator and if not resolved there, to mandatory and binding arbitration. Similarly, if a dispute arises over the relative intellectual contribution to an innovation, a third party expert is brought in to resolve the dispute.

Having a good dispute resolution process relieves the pressure to attempt dealing with the unknowable. In the end, the goal should be a relationship of trust where if one has to ever pull out the master agreement after it is signed, something has gone wrong.

Intellectual property provisions. There is a vast literature on attempting to resolve the IP considerations when engaging with private sector companies in research and I don't want to repeat it here. These are difficult and complex issues.

The respective interests change depending on whether the research is jointly funded or individually funded by the company and the extent to which either of the parties brings background technical information to the research. There are several models. In the ideal world, the parties can agree on a mechanism that is based on objective criteria 
and is essentially automatic with no room for disputes around valuation or likely commercial success. One has to remember that a private sector research partner may be more sensitive to the competitive advantage of a technology than they are to the market value of that technology.

In the end, the terms will likely be driven by whether the university regards its involvement in these relationships as short-term or long-term. In one-off licensing deals, I have always thought the University should be fairly compensated for its innovation. In longer term relationships, there are often returns beyond royalties that may suggest a less aggressive posture. And establishing a methodology avoids the costs of constant negotiation over IP rights for each innovation that is produced by the joint enterprise.

Faculty, of course, have significant concerns going into a research relationship with a private company. Since under our rules the faculty member is entitled to a share of the licensing or other revenue from an innovation, the IP terms are of personal interest. But they also want to be assured their inherent skill and experience is not exclusively acquired by a single company - that they are free to engage with other companies on similar but unrelated projects. One has to assure faculty that the University is not selling them into indentured servitude and one has to fight hard on their behalf to make sure this doesn't happen.

Organizational Structure. As I have alluded to, the returns on the investment in private sector relationships can come in many forms, sometimes in unusual and unexpected ways. This is particularly true in longer term relationships but sometimes in one-off transactions as well. In organizing our effort to engage with the private sector we have created what is perhaps a structure that is idiosyncratic and based more on the personnel in place rather than on any organizational theory.

We have two separate 501(c)(3) companies managed by separate boards with a majority of private sector members. We have spun off the commercialization of faculty innovations into NUtech Ventures, a private company with a mixed board of directors from the university and the private sector. As I have mentioned, we also have a separate company with a separate board and CEO managing Innovation Campus. We also have an "industrial relations" unit of our Office of Research and Economic Development designed to foster private sector research engagements.

In one of our negotiations with a major international company to license University technology, we ended up accepting a license royalty, a significant philanthropic gift, and a research agreement, all within the same transaction. And we still have some hope they may locate on Innovation Campus. It was not rocket science to realize that one ought to think holistically about relationships with the private sector. The key is the relationship and benefits can flow in both directions in a variety of different forms. Initially we worried that the natural instinct of the CEO of NUtech Ventures, for example, would be to channel a company's interests toward licensing technology and the head of Innovation Campus would push toward a physical presence on the property. This circumstance is not likely to maximize the University's interest. 
We have created a team approach where all three directors get credit for an engagement with a private sector company regardless of the nature of that engagement. We have a bonus plan where individual bonuses are calculated on the overall success of our engagement with a private company. It's not clear to me this would work were it not for the personalities of the people involved. The point though is that when engaging the private sector one ought to have multiple definitions of success and eliminate barriers that may reduce the overall returns to the University.

In conclusion, I think we are far beyond the question of whether we should engage with the private sector in research partnerships. I believe that is a given and a necessity. However, there remains much to be considered in how these relationships are structured, implemented, and assessed. Getting these items right will have a lot of influence on the future of our research enterprise. 